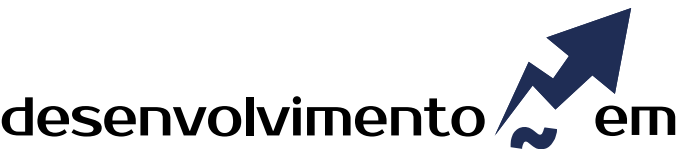 QUESTÂOO
}

\section{A Legislacão e a Nova Agenda Urbana: Aporte para a Gestão das Cidades e de Atividades Econômicas}

http://dx.doi.org/10.21527/2237-6453.2018.45.6-25

Recebido em: 29/8/2017

Aceito em: $13 / 4 / 2018$

Rógis Juarez Bernardy ${ }^{1}$, Rogério Leandro Lima da Silveira ${ }^{2}$

\begin{abstract}
RESUMO
Diversos fatores influenciam na dinamicidade de uma cidade, tais como as características demográficas, a diversidade de atividades econômicas e a espacialização dos setores produtivos no ambiente urbano, a formação urbana horizontal unifamiliar e vertical mista e as condições da legislação municipal, que regulamenta e induz o uso do solo urbano. A legislação relacionada ao planejamento é particularmente interessante, pois, por um lado, possui menor capacidade de influenciar em áreas urbanas centrais, com usos mais consolidados; por outro, apresenta expressiva potencialidade para induzir o desenvolvimento em áreas urbanas orgânicas, em constante transformação, chamadas de policêntricas e não centrais. Esta pesquisa visa a analisar a funcionalidade urbana vinculada à produção econômica por comércio, indústria e serviço, a partir de estudo das determinações legais contidas nos Planos Diretores de três cidades médias, localizadas no Sul do Brasil: Passo Fundo (RS), Chapecó (SC) e Cascavel (PR). Enquadra-se como uma pesquisa qualitativa com base em fontes de legislações de Planos Diretores municipais, quanto à produção do uso do solo por atividades econômicas e sua conformidade com o Estatuto da Cidade (2001). Como resultados observou-se que as legislações são flexíveis, indutoras do desenvolvimento urbano, pois permitem o uso do solo multifuncional, híbrido ou miscigenado, portanto, não são regulamentadoras, embora pouco vincule os instrumentos do Estatuto da Cidade (2001) para a produção do uso do solo para atividades econômicas, particularidade que poderia auxiliar na organização urbana e em orientações de investimentos econômicos futuros nessas cidades.
\end{abstract}

Palavras chave: Plano Diretor. Gestão urbana. Espacialização de setores econômicos urbanos.

\section{LEGISLATION AND THE NEW URBAN AGENDA: CONTRIBUTION FOR THE MANAGEMENT OF CITIES AND URBAN ECONOMIC ACTIVITIES}

\begin{abstract}
Several factors influence the dynamicity of a city, such as the demographic characteristics, the diversity of economic activities and the specialization of the productive sectors in the urban environment, the single-family horizontal and mixed vertical urban formation, and the conditions of the municipal legislation that regulates and induces the use of urban soil. The legislation related to planning is particularly interesting, since on one hand it has less capability of influencing in central urban areas, with more consolidated uses, on the other hand, it presents expressive potentiality to induce the development in organic urban areas, constantly changing, called polycentric and non-central. This research aims at analyzing the urban functionality linked to the economic production by trade, industry, and service, from studies of the legal determinations embodied in the Directive Plans of three medium-sized cites situated in the South of Brazil: Passo Fundo (RS), Chapecó (SC), and Cascavel (PR). It fits in as a qualitative research based on sources of legislations of municipal Directive Plans regarding the production of the use of the soil by economic activities and in conformity with the City Statute (2001). As a result, it was observed that the legislations are flexible, fomenters of the urban development, for they enable the use of multifunctional, hybrid, or blended soil, therefore, they are nor regulatory, although they poorly link the instruments of the City Statute (2001) for the production of the use of the soil for economic activities, a particularity that could help in the urban organization and in orientations of future economic investments in these cities.
\end{abstract}

Keywords: Directive Plan. Urban management. Specialization of urban economic sectors.

\footnotetext{
${ }^{1}$ Doutor em Engenharia Civil, área de Cadastro Técnico Multifinalitário e Gestão Territorial, pela Universidade Federal de Santa Catarina. Professor do Programa de Pós-Graduação em Administração da Universidade do Oeste de Santa Catarina.rogis.bernardy@unoesc.edu.br

2 Doutor em Geografia Humana pela Universidade Federal de Santa Catarina. Professor do Programa de Pós-Graduação em Desenvolvimento Regional da Universidade de Santa Cruz do Sul. rlls@unisc.br
} 
As cidades médias desempenham importante papel na estrutura da rede urbana brasileira, e por sua posição contribuem para um maior equilíbrio regional, inclusive suprem funções atípicas, pela ausência de grandes centros urbanos nas proximidades. Além do aumento populacional (que ainda persiste), tendem a ampliar as atividades econômicas no seu interior, tais como no comércio, serviços e indústrias. Esta configuração tem contribuído para que surjam novos ambientes de produção do uso do solo urbano para as atividades econômicas (cidades policêntricas), em detrimento da perda de vitalidade da área urbana central (monocêntrica).

A preocupação com o ordenamento das atividades econômicas é uma das pautas mais importantes nos processos de planejamento e organização das cidades, principalmente as médias, que também se constituem de centralidades regionais, portanto locais com capacidade de oferecer oportunidades de trabalho e renda mais diversificadas em relação aos municípios pequenos. Um dos instrumentos importantes para a equidade dos custos urbanos e da melhoria da qualidade de vida dos munícipes é representado pelas oportunidades geradas pela Lei 10.257/01, denominada de Estatuto da Cidade (2001), que regulamentou os artigos 182 e 183 da Constituição Federal (1988).

Para além dos espaços de produção econômica tradicional, vinculados aos centros geo-histórico urbano, um desafio consiste na integração e desenvolvimento de atividades produtivas que não gerem conflitos, que não aumentem os custos fixos da cidade, pela necessidade de instalação de infraestrutura e demais equipamentos públicos, contribuindo para a efetiva descentralização do desenvolvimento, com base nestes novos ambientes de centralidade urbana, entendida como a diferenciação espacial, que corresponde às variadas intensidades e diversidades de atividades econômicas urbanas (KRAFTA, 1997).

Esta pesquisa tem como objetivo analisar a funcionalidade urbana vinculada à produção econômica por comércio, indústria e serviços, a partir de estudo das determinações legais contidas nos Planos Diretores de três cidades médias, localizadas no Sul do Brasil: Passo Fundo (RS), Chapecó (SC) e Cascavel (PR). A análise dos Planos Diretores tem como finalidade compreender as características legais e as respectivas influências na evolução do uso do solo urbano, quando da existência de setores prioritários para a produção econômica, tanto em área urbana central (monocêntrica) quanto em ambientes de previsão de descentralização do desenvolvimento (policêntrica), bem como suas interfaces. Este entendimento pode orientar investimentos futuros, tanto pela iniciativa privada quanto para o gerenciamento da infraestrutura e equipamentos públicos urbanos.

No processo metodológico definiu-se como uma pesquisa qualitativa com base em fontes de legislações de Planos Diretores municipais (elaborados em 2006, 2013 e 2014, respectivamente), no que diz respeito à produção do uso do solo por atividades econômicas e sua conformidade com o Estatuto da Cidade (2001). Também foram estudadas as características da aplicabilidade do Plano Diretor à realidade municipal, se possuem abrangência territorial, com enfoque urbano, se ordenadas em macrozonas e zoneamentos. A análise deste conteúdo permitiu a elaboração de um quadro-síntese com as características dos três municípios, que podem orientar investimentos futuros nas respectivas áreas urbanas, entendendo que esta legislação tem uma durabilidade de 10 anos. 
A estrutura desta pesquisa, que além desta seção introdutória é composta pela revisão bibliográfica, que utilizou referenciais que proporcionaram um suporte para a compreensão e alinhamento da pesquisa, também contempla os procedimentos metodológicos, que demonstraram a estrutura lógica e o desencadeamento instrumental, seguido da apresentação e análise dos resultados, finalizada por quadro-síntese com os elementos de análise, da conclusão e das respectivas referências.

\section{CIDADE MÉDIA MONOCÊNTRICA E POLICÊNTRICA}

Os ambientes urbanos em seus processos evolutivos possuem forte relação com a concentração de atividades econômicas em suas áreas centrais. Desta forma, representam elementos de estruturação e de dinamização do ambiente construído, não raro de conflitos entre os interesses que norteiam o produzir e o habitar na cidade. A evolução dos equipamentos de produção de comércio, serviços e atividades industriais está diretamente relacionada à própria evolução urbana das cidades (SCHÄEFFER, 1993).

No que diz respeito à dinamicidade econômica, independentemente dos critérios de definição conceitual, as cidades médias têm-se apresentado como importantes espaços no âmbito da rede urbana brasileira. Sobretudo em locais que experimentam profundas reestruturações internas de seu espaço territorial, elas podem favorecer e potencializar a diminuição de disparidades regionais, contribuindo para a formação de um sistema urbano mais equilibrado, além de oferecerem qualidade de vida aos seus habitantes, portanto apresentam-se como "ambiente de articulação e de equilíbrio de uma rede de cidades" (RAMOS; MATOS; GARCIA, 2011).

As cidades médias estão localizadas na seção intermediária da rede urbana e para além de seu porte e funções, que podem ser determinados pelo tamanho populacional, morfologia urbana e diversidade de atividades econômicas, principalmente no setor comercial, industrial e de serviços, de acordo com a região de inserção, outros elementos mais peculiares são fundamentais para a sua classificação: i) intensidade de fluxos com os demais ambientes urbanos - rede de cidades; ii) capacidade de estabelecer relações de dinamização com o ambiente rural; iii) a rede de cada cidade média apresenta uma intensidade e um grau de conectividade que facilitem as já referidas interações; iv) estrutura morfológica interna, em consonância com sua posição no processo de evolução; v) tamanho demográfico, estrutura interna e relações externas das cidades médias podem variar de uma região para outra, sendo naturalmente função do nível de desenvolvimento, da posição geográfica e das condições histórico-sociais da formação de cada uma dessas regiões (CASTELLS, 2006); vi) não deve ser confundida necessariamente com a noção de centro de polarização regional ou microrregional, podendo haver relação de complementaridade (AMORIM FILHO, 1976; INSTITUTO..., 2014).

Embora não represente uma linearidade e podendo haver a coexistência de mais de um equipamento econômico (inclusive na mesma temporalidade), é interessante observar certa evolução no padrão da produção econômica das cidades médias: permuta de mercadorias, feiras, casas comerciais (laços de proximidade espacial), armazéns, galerias, mercados (perda gradativa dos laços de proximidade espacial), supermercados, lojas de departamentos, centros comerciais, hipermercados e shopping centers (rompimento dos laços de proximidade espacial). Observa-se que nestes últimos existe um 
rompimento na proximidade dos espaços urbanos, fator importante para a descentralização do desenvolvimento econômico (policêntrico) e para a desvitalização dos centros históricos e econômicos urbanos (monocêntrico) (Figura 1).

Figura 1 - Fases comuns das atividades econômicas urbanas em cidades médias

\begin{tabular}{|c|c|c|c|c|c|c|c|c|}
\hline $\begin{array}{l}\text { Permuta } \\
\text { Mercadoria }\end{array}$ & Feiras & $\begin{array}{c}\text { Casas } \\
\text { Comerciais }\end{array}$ & $\begin{array}{l}\text { Armazéns } \\
\text { esquina }\end{array}$ & $\begin{array}{c}\text { Galerias } \\
\text { comerciais }\end{array}$ & Mercados & $\begin{array}{l}\text { Super- } \\
\text { mercados }\end{array}$ & $\begin{array}{l}\text { Hiper- } \\
\text { mercados }\end{array}$ & $\begin{array}{l}\text { Shopping } \\
\text { center }\end{array}$ \\
\hline \multicolumn{3}{|c|}{ Laços de proximidade espacial } & \multicolumn{3}{|c|}{$\begin{array}{c}\text { Perda gradativa dos laços de pro- } \\
\text { ximidade espacial }\end{array}$} & \multicolumn{3}{|c|}{$\begin{array}{c}\text { Rompimento dos laços de proxi- } \\
\text { midade espacial }\end{array}$} \\
\hline \multicolumn{3}{|c|}{ Ambiente Monocêntrico } & \multicolumn{3}{|c|}{ Transição } & \multicolumn{3}{|c|}{ Ambiente Policêntrico } \\
\hline
\end{tabular}

Organização: Autores da pesquisa, 2017.

As cidades, na atualidade, são cada vez mais descentralizadoras nas suas formas espaciais, tanto no que diz respeito aos novos loteamentos e empreendimentos imobiliários residenciais, mistos ou comerciais e de serviços, quanto para as atividades industriais, que buscam se estabelecer em áreas fora do centro tradicional (monocêntrico). Assim, as cidades caracterizam-se cada vez mais como descontínuas, posto que em lugar de uma unidade espacial do tecido urbano continuada o que se encontra é uma "ruptura da unidade territorial das cidades" (SPOSITO, 2010, p. 126 apud GOMES, 2015; FERRÃO, 2012), com reflexos na espacialização das atividades econômicas.

$\mathrm{Na}$ organização intraurbana das cidades médias, os centros urbanos são "[...] um conjunto vivo de instituições sociais e de fluxos de uma cidade real, locais que apresentam extremo valor de uso para fins de produção econômica" (VILLAÇA, 2001, p. 238). Quando concentradores de atividades econômicas comerciais, de serviços e industriais de pequeno porte, são geradores de um movimento dialético, uma vez que em período pretérito, os demais usos foram realocados para ambientes "menos nobres" e a própria densidade destas atividades ocasiona a desvitalização destes espaços centrais. Entre as características dos centros urbanos monofuncionais citam-se: hiperutilização da infraestrutura urbana em horário comercial; subutilização urbana em período noturno; vias de circulação com mobilidade precária; falta de estacionamento público; dificuldades de acessos em edificações mistas; ambiente relativamente hostil para a moradia; problemas de segurança pública; falta de renovação urbanística; evolução de atividades comerciais apenas para a população de menor poder aquisitivo.

Para Villaça (2001, p. 238), “[...] toda aglomeração, desenvolvida precisamente para gerar aproximação, gera afastamento", neste caso, a espacialização central das atividades econômicas gera o afastamento dos trabalhadores, que configuram os "deslocamentos espaciais regulares ou gentrification [...] e disputas ocorrem por localização em função do domínio do controle do tempo nos deslocamentos espaciais" (Ibid., p. 239). "O centro tradicional, o monocêntrico, por mais notória que seja a sua decadência, continua sendo o foco irradiador da organização espacial urbana" (Ibid., p. 246), por sua condição de concentração de atividades econômicas, atração de fluxos ou drenagem populacionais e valor simbólico que (ainda) representa.

O fenômeno policêntrico ocorre em um território urbano que tende a se agrupar em vários centros de atividades. Em princípio estruturam-se atividades de comércio de alimentos, para o atendimento parcial da população local, não raro consorciado com a presença de equipamentos públicos e comunitários, tais como unidade de saúde, 
creche, escola e centro de uso comunitário. Ele reflete o dinamismo das cidades caracterizado pela descentralização das atividades econômicas, aumento da mobilidade, complexo cross-commuting (deslocamentos ou mobilidades transversais) e distribuição espacial fragmentada de atividades e para as firmas cria vantagens comparativas e de aglomeração (GEYER, 1998; DAVOUDI, 2003 apud PESSOA, 2011).

A aglomeração urbana policêntrica possui fronteiras dinâmicas, portanto não estáticas, dado que seus limites não são mais fixos, como um bairro ou loteamento, perfeitamente delineado. "A transição das fronteiras não é clara, sendo definida por gradiente dinâmico de fronteiras e não mais por uma linha estática" ou um polígono, um buffer (PESSOA 2011, p. 305), uma vez que, além das determinações legais que definem esta flexibilidade em suas fronteiras (miscigenação de usos em Plano Diretor flexível), é fortemente influenciada "[...] pela multiplicação das atividades comerciais e de serviços" (SPOSITO, 2004, p. 115).

Estes polinúcleos complementares de produção econômica podem ser motivados por vários fatores, entre os quais a previsão de novos parcelamentos do solo com usos multifuncionais, híbridos ou miscigenados, desde que a legislação municipal tenha esta flexibilidade; locais próximos do centro urbano provido de certa infraestrutura que permita o desenvolvimento de atividades econômicas (pode manter certos vínculos com o ambiente monocêntrico); instalação de novos equipamentos urbanos, tais como supermercados, hipermercados e shopping centers; instalação de infraestrutura urbana, como vias perimetrais de ligação entre bairros, unidades de saúde, demais edificações públicas; flexibilização da legislação municipal que regulamenta o uso do solo, como o Plano Diretor, o Código de Parcelamento do Solo Urbano; acessos urbanos e de ligação entre bairros, que permitem uma flexibilização da mobilidade e vias de ligações regionais (tecnicamente chamados de corredores de centralidade e que originam policentros lineares, portanto não poligonais).

Em designação similar para polinúcleos, para Villaça (2001, p. 293) “[...] exercem uma atração, ou polarização, mais constante sobre um número maior de pessoas", neste caso, a proximidade geográfica e a maior identidade das atividades econômicas com o lugar determinam a maior atratividade. Por um lado, existe uma perspectiva de "diminuição da densidade relacional" (minimização das relações) no ambiente monocêntrico, por outro, o "aumento da densidade relacional" (ampliação das relações pelo aumento da intensidade e da densidade de atividades econômicas) no ambiente policêntrico das cidades médias.

Keynhans (2001 apud Colling; Piffer, 2016) mencionam elementos que são características essenciais para o ativamento de uma centralidade: de primeira ordem, a acessibilidade por meio do transporte, o uso do solo, os fatores econômicos e sociais locais. Acrescenta-se o ativamento de segunda ordem, como as condições locacionais, ambientais, de infraestrutura, institucionais, de participação (capital social, pelos vínculos empresariais e associações representativas de setores econômicos), entre outras (FONTES FILHO; BRONSTEIN; PIMENTA, 2015; COLLING, PIFFER, 2016). Também existem as condições legais, determinadas pela legislação municipal indutora do desenvolvimento urbano - este item foi omitido pelos autores - que poderia ser o ativamento de terceira ordem. 
Para a consolidação de um policentro existe a necessidade de "identidade de bairro ou sentimento de pertencimento" por parte de um conjunto de agentes socioeconômicos. Neste contexto é primordial a presença institucional pública, por meio dos equipamentos públicos e comunitários e pela aplicação da legislação flexível, não regulatória, que incentiva o parcelamento do solo urbano de forma miscigenada. Este fenômeno está em conformidade com o que se conhece pela "nova agenda urbana", que se caracteriza por uma cidade mais compacta, integrada, portanto menos segregada e socialmente inclusiva.

Nesta seara, para Pujadas e Font (1998, p. 293-294), “El espacio urbano, muy diferenciado, em el que coexisten grand variedad de usos del suelo y dentro del qual se distinguen dos grandes categorias que son a la vez excluyentes y complementarias: los espacios libres e públicos e los espacios parcelados". A partir desta complexidade a interferência por meio do planejamento urbano deve "assegurar que a propriedade garanta a sua função social, e de forma sistemática, refletiria no cumprimento da função social da cidade, com base na efetiva incorporação dos instrumentos do Estatuto da Cidade", mesmo que de forma gradativa (SOUZA, 2004).

Visando a reverter os processos de segregação urbana em ambiente com uso do solo complexo, diversificado, e por vezes conflitantes, em vez de se ter como princípio geral a restrição detalhista e a monotonia ou monofuncionalidade de usos, no Plano Diretor, o princípio a ser observado no uso do solo urbano deverá ser a miscigenação de usos. Souza (2004, p. 266-267) denomina de "espírito funcionalista, a liberdade de regra com a restrição sendo prevista apenas onde realmente for necessária, e a mistura ou miscigenação de usos deve ser prioritária", são as chamadas unidades funcionais urbanas.

Neste caso específico, para a utilização do uso do solo urbano prioritário, para fins comerciais, serviços e atividades industriais não restritivas, aliada aos usos residenciais, unifamiliares e multifamiliares, que permitem uma verticalização urbana, deveria ser considerada e condicionada à capacidade de suporte urbano em virtude da infraestrutura previamente instalada, como um critério essencial para a efetivação de atividades econômicas e de uma densidade adequada de pessoas (uso residencial) no espaço urbano.

Quanto à produção econômica do espaço urbano, não é possível a coexistência de toda e qualquer atividade circunvizinha. Como exemplo cita-se a necessidade de normatizar e regulamentar a localização de atividades industriais poluentes, independentemente do seu tamanho, sendo que, neste caso, a legislação municipal deve ser restritiva, visando à qualidade de vida da população e à economia municipal. Para Souza (2004, p. 265), "controlar a localização de algumas atividades faz sentido, do ponto de vista da salvaguarda dos interesses coletivos", como já mencionado, "que necessitam ter a sua localização no espaço da cidade (ou em um corredor de acesso regional e urbano), regulamentada criteriosamente" (Ibid., p. 245). "Embora as atividades urbanas (o uso do solo em geral) sejam complementares em termos agregados, existem inúmeros incômodos associados à contiguidade de usos incompatíveis" (CARVALHO PINTO, 2011, p. 46). 
Neste sentido, por um lado, a segregação urbana também pode ser acrescida pelas características do planejamento municipal, o qual pode reforçar os elementos segregatórios internos da cidade; por outro, as novas formas de usos do solo miscigenadas tendem a desintensificar a segregação urbana. Por essa razão a próxima seção, faz uma análise da constituição e da agenda do planejamento e da gestão urbana brasileira.

\section{Agenda do Planejamento e da Gestão Urbana}

Uma opção para reverter os processos de conflitos e o encarecimento urbano está relacionada à regulamentação dos artigos 182 e 183 da Constituição Federal (1988) que trata sobre o desenvolvimento urbano, com base na aplicação do Estatuto da Cidade e seus respectivos instrumentos que implicam em "[...] diretrizes e preceitos sobre Planos e planejamento urbano, sobre gestão urbana e regulação estatal e jurídica [...] participação social nos planos, orçamentos, leis complementares e parcerias público-privadas" (MARICATO, 2010, p. 6). Para Meirelles (1993, p. 395 apud Ferrari, 2012, p. 230), "o Plano Diretor [...] deve ser a expressão das aspirações dos munícipes quanto ao progresso no território municipal", inclusive o espaço rural, pois deve almejar dois objetivos principais: qualidade de vida e custos urbanos e municipais equitativos e adequados à realidade social.

A abordagem adequada dos temas no Plano Diretor deve- contemplar, em especial, a previsão de crescimento urbano por meio do desenvolvimento econômico, as redes de infraestrutura e de serviços públicos, as limitações urbanísticas para as edificações com fins econômicos ou mistos, a preservação ambiental e a gestão democrática e participativa, entre outros (esta listagem apresenta apenas alguns dos temas com aderência na parte da produção do solo urbano, pelas atividades econômicas). O Plano Diretor é uma lei complementar municipal da maior importância, pois estabelece as diretrizes e as regras a serem cumpridas para o desenvolvimento planejado do município, por um período máximo de dez anos, revelando-se uma construção com a participação de especialistas e da comunidade, portanto se constitui como uma política municipal e não de governo (ESTATUTO..., 2001; MARICATO, 2010).

Um fator essencial para a efetividade de um Plano Diretor diz respeito ao seu processo de elaboração, uma vez que necessita ser embasado na realidade local, sem a transferência de modelos padronizados, com a realidade diferente e previamente executada. Deve ser focado em temáticas que apontam para o desenvolvimento de projetos e investimentos que se convertam em melhoria na qualidade de vida da população, não atenda apenas a interesses de grupos hegemônicos e a diminuição dos custos fixos urbanos, tanto na efetivação quanto na manutenção de infraestrutura.

O planejamento de um município deve caracterizar-se por três esferas: a legal ou jurídica, a técnica e a social ou comunitária. A jurídica diz respeito à análise de todas as condicionantes e características legais, em diferentes esferas; a técnica está relacionada às informações locais que servem de base para a prospecção territorial; a social ou comunitária (política) relaciona-se à mobilização comunitária, à participação dos agentes públicos, das entidades representativas, da comunidade (como exemplo, no Núcleo Gestor e a audiência pública), tanto no processo de elaboração quanto de fiscalização 
na aplicação do Plano Diretor. Quanto ao Plano Diretor, deve conter "[...] um conjunto de novos instrumentos de natureza urbanística voltados para induzir, mais do que normatizar, as formas de uso ocupação do solo urbano" (SAULE JUNIOR; ROLNIK, 2001).

Nesta concepção, entende-se que as dimensões técnica e jurídica constituem os pilares do planejamento e as comunitárias ou sociais da gestão do desenvolvimento como dimensões que se complementam. No caso do Plano Diretor é adequado, imprescindível e legal o envolvimento comunitário, também no processo de elaboração, para a contribuição em razão do conhecimento empírico que a sociedade possui sobre o ambiente que está sendo planejado e pela organização comunitária (embora em determinados casos seja precária, inexistente ou uma pseudoparticipação - induzida).

Entre estes benefícios está a contemplação legal da participação popular, garantida no Estatuto da Cidade (2001), "que se constitui em um avanço na trajetória do desenho de planejamento e gestão participativos do espaço urbano, ao instituir as diretrizes e os instrumentos com vistas a atingir o objetivo da função social da cidade e da propriedade urbana" (ANTONELLO, 2013, p. 242). O Estatuto da Cidade "proporciona o respaldo jurídico para o planejamento e gestão democráticos das cidades", com base no que a autora chama de "planejamento com diálogo" com a sociedade, portanto, com integração social (Ibid., p. 242). Embora esta participação seja ainda embrionária, em algumas situações até bastante deficitária, já representa um avanço cultural e qualitativo importante e pode ser muito potencializada no futuro da governança participativa das cidades brasileiras.

O Plano Diretor como mecanismo para a gestão para a sustentabilidade municipal tem sido discutido desde que a comunidade internacional, liderada pela Organização das Nações Unidas (ONU), que abordou a temática do desenvolvimento nas reuniões de cúpula e das conferências temáticas globais. O Programa Cidades Sustentáveis (2012) apresenta indicadores relativos à sustentabilidade sugeridos por diferentes programas e relacionados à gestão urbana: governança, preservação dos bens comuns, equidade no desenvolvimento urbano, com base em planejamento e gestão para a sustentabilidade, economia local dinâmica e diversificada, criativa, empreendedora e inovadora e mobilidade (BRANDLI et al., 2015).

Sobre a integração e complementaridade entre o planejamento e a gestão, destaca-se que "o processo de gestão é a efetivação, das condições que o planejamento prévio aportou, desta forma, o planejamento e a gestão são distintos e complementares" (SOUZA, 2004, p. 46), embora se reconheça que, independentemente do tamanho e funções da cidade, existe uma série de tomadas de decisão desprovidas de planejamento prévio, também no que está vinculado à política urbana. Nesse sentido, "a política urbana é o setor de atuação que trata da ordenação do território das cidades, mediante a alocação do recurso entre os diferentes usos que o disputam" (CARVALHO PINTO, 2011, p. 44).

Na sustentabilidade urbana a cidade é vista como espaço de legitimação das políticas, e pode ser expressa pelo modelo de eficiência na gestão dos recursos públicos e pela equidade na disposição em democratizar o acesso aos serviços urbanos, demonstrando a capacidade na gestão das cidades na adaptação da oferta de serviços que visam atender as demandas da sociedade (ACSELRAD, 2009). Esta se constitui como a terceira matriz da sustentabilidade urbana de Acselrad (2009), ou seja, a cidade como 
ambiente de legitimação de políticas públicas, precedida da cidade como vetor de consumo de espaço (segunda matriz) e a cidade como espaço de qualidade de vida (primeira matriz).

No âmbito da gestão e do planejamento são as decisões que desencadeiam os projetos e as ações que, de alguma forma, interferem diretamente no espaço da cidade e na sua dinâmica, tais como: efetivação da infraestrutura, instalação de um novo grupo de atividades comerciais e de serviços em um local específico, que crie novas possibilidades de atividades econômicas, tornando a cidade policêntrica, a demanda por sistemas de transportes, entre outros (SABOYA, 2013). A atração e fixação de atividades diferenciadas, mais dinâmicas, representa um importante catalisador de desenvolvimento das cidades médias, principalmente em centralidades urbanas aptas ao recebimento desse tipo de investimento, condição que pode ser pactuada com base na tomada de decisão compartilhada entre agentes públicos e privados, visando a uma política municipal de desenvolvimento econômico, inclusive com amparo social (gestores públicos, empreendedores e líderes de entidades e comunitários).

O município, inclusive, pode criar uma política de apoio ao desenvolvimento econômico, específica para estas centralidades, pautadas em empresas de conhecimento intensivo, como na inovação, tecnologia, pesquisa, aporte à melhoria ambiental e empresas que complementam as cadeias produtivas atuais. No contexto dessas estratégias de desenvolvimento urbano, "creating an economic development strategy that responds to the changes in the economy: it will be vital for medium-sized cities to consider how they can attract and grow private sector knowledge-intensive services firms [...] (CLAYTON; MORRIS, 2010, p. 5).

Para Leite e Award (2012, p. 9), a democratização das informações do território urbano com "os novos sistemas de informações, tecnologias e comunicações deve favorecer a formação de comunidades participativas, além de e-governance: serviços de governo inteligentes, mais ágeis, transparentes e eficientes, pelo compartilhamento de informações". Para os autores, as "cidades inteligentes, smart cities, podem e devem alavancar a equalização da vida urbana, seja com serviços avançados na cidade formal, seja com novas oportunidades nos territórios informais" (Ibid., p. 9).

Nesta seara, por um lado, as áreas urbanas centrais parecem sofrer uma espécie de "enclausuramento compulsório" e essa segregação, em parte, se dá pela própria especialização do uso do solo, portanto da sua própria evolução histórica e econômica. Processos de gestão efetivos para antecipar a desvitalização de áreas urbanas centrais monocêntricas não têm sido evidentes de forma sistemática, principalmente em cidades médias.

Por outro, as novas centralidades representam um desafio para a sua gestão, uma vez que evoluíram do uso do solo predominante residencial, portanto, monofuncional, e a gestão de ambientes policêntricos devem ser direcionadas as suas especificidades, para evitar que apresentem problemas estruturais típicos de centros urbanos em processos de desvitalização, tais como na deficiência de corredores de transporte coletivo, carência de estacionamentos, conflitos e excessos na utilização das vias públicas, substituição irreversível das residências pelo comércio e serviços, pela elevação da valorização imobiliária. 


\section{PROCEDIMENTOS METODOLÓGICOS}

Esta seção está centrada na demonstração das características que nortearam a análise e as respectivas influências na evolução do uso do solo urbano, quando da existência de setores prioritários para a produção econômica, em ambiente urbano de Passo Fundo (RS), Chapecó (SC) e Cascavel (PR), três cidades médias. Efetivou-se uma análise detalhada de todas as contemplações legais compostas nos Planos Diretores relacionadas ao uso do solo urbano em área monocêntrica e policêntrica, por atividades industriais, comerciais e de serviços (podem ser mescladas com outros usos, neste caso, se constituem como mistos), portanto, os demais usos, como o residencial, institucional, com finalidade ambiental, e demais, não foram objetos de análise desta pesquisa.

As principais especificidades que motivaram a pesquisa são as seguintes: as três cidades médias possuem afastamento geográfico de grandes centros urbanos, o que Ihes proporciona maior relevância para os padrões de suas organizações espaciais internas; constituem-se como polos de comando e intermediação regional; são ambientes centrais de vastas regiões compostas por poucas cidades medianas e grande quantidade de pequenas cidades; possuem atores econômicos urbanos que não se articulam somente com o regional, desenvolvem "saltos de escalas espaciais" e se articulam com o mercado internacional - circuito espacial do agronegócio; tiveram processos evolutivos confinados às atividades do agronegócio vinculadas às atividades da indústria urbana; são ambientes urbanos menos articulados com a divisão intraurbana do trabalho; constituem-se também como centros de suas respectivas regiões, pela diversidade de atividades industriais, comerciais e serviços especializados (público e privado) e das redes de interconexões regionais; constituem ambientes urbanos que "confinam" a renda fundiária regional, que impactam no valor do uso e de troca do solo urbano, tanto para uso de atividades econômicas quanto para uso residencial.

A pesquisa caracteriza-se como qualitativa, pois inclui um conjunto de técnicas interpretativas que procuram descrever, traduzir, apreender o significado e analisar fenômenos ocorrendo com certa naturalidade com o ambiente das organizações e instituições ou de cidades, permite construir respostas que são codificadas e comparadas, para o entendimento dos ambientes da pesquisa (COOPER; SCHINDLER, 2011). Efetivou-se uma análise detalhada dos três Planos Diretores e toda vez que algum artigo remetesse ao escopo principal da pesquisa, ou seja, ao uso do solo urbano em área monocêntrica e policêntrica, por atividades econômicas, efetivou-se uma interpretação e análise de conteúdo desse texto legislativo e sua perspectiva de aplicabilidade à realidade municipal (cidade real).

Quanto à coleta de informações, constou de observação técnica in loco nos três ambientes e de análise nas bases de informações legais: Lei n. 170, de 2006 - Plano Diretor de Passo Fundo (RS); Lei n. 541, de 2014 - Plano Diretor de Chapecó (SC); Lei n. 028, de 2013 - Plano Diretor de Cascavel (PR), este complementado pela Lei n. 6179, de 2013 - Uso do Solo no Município de Cascavel (PR). Esta análise in loco ocorreu entre janeiro e maio de 2017, nas três cidades, como forma de observar as características físicas e espaciais (tipo de uso do solo urbano por atividade econômica; caracterização das atividades econômicas, padrão das edificações, caracterização dos lotes urbanos e 
padrões da urbanização) dos três ambientes da pesquisa, no que diz respeito ao uso do solo por atividades econômicas, visando a encontrar especificidades e particularidades nos três ambientes da pesquisa.

Nas legislações analisou-se em detalhe: a caracterização do ordenamento do solo, da área urbana central, a revitalização da área urbana central, contemplação de área urbana descentralizada, laços de solidariedade entre ambiente monocêntrico e policêntrico, flexibilidade de usos ao invés de zoneamentos no Plano Diretor, miscigenação do uso do solo urbano, atividades de produção econômica fora do perímetro urbano, aplicação dos instrumentos do Estatuto da Cidade (2001) e a existência de vínculo entre os instrumentos do Estatuto da Cidade (aspecto legal) com o uso do solo por atividades econômicas.

\section{APRESENTAÇÃO E ANÁLISE DOS RESULTADOS}

A análise dos Planos Diretores tem como finalidade a compreensão das características legais e as respectivas influências na evolução do uso do solo urbano, quando da existência de setores prioritários para a produção econômica, na área urbana central, portanto, monocêntrica e em ambientes de (previsão) descentralização do desenvolvimento, ou seja, áreas policêntricas, bem como suas interfaces, considerando que a cidade média constitui-se como um ambiente orgânico, em constante transformação.

Para além da especificidade de terem conformidade com o Estatuto da Cidade (Lei 10.257/01), os três Planos Diretores apresentam características espaciais próprias, de cada ambiente urbano (e municipal), e ainda podem ser influenciados pela temporalidade da elaboração (a assimilação da aplicação dos instrumentos do Estatuto da Cidade), quantidade e qualidade da produção das informações e dados, caracterização da equipe técnica e visão sistêmica sobre a cidade, integração dos gestores municipais ao processo de elaboração da legislação, interferências de grupos sociais com visão privilegiada quanto à produção do solo urbano, qualidade do envolvimento e da participação social, entre outros.

\section{Uso do Solo Monocêntrico e Policêntrico no Plano Diretor de Passo Fundo (RS)}

O município de Passo Fundo (RS), localizado no Noroeste Rio-Grandense, foi instalado em 1857 e possui uma população de 198.799 pessoas, conforme a estimativa do IBGE (2017). Sua base econômica é o agronegócio, que influencia em uma diversidade de atividades industriais urbanas, no comércio e serviços prestados para o âmbito regional, o que determina uma diversidade de usos, que refletem no processo de transformação intraurbana da cidade.

O Plano Diretor de Desenvolvimento Integrado (PDDI) de Passo Fundo (RS) foi instituído pela Lei municipal n. 170, de 2006, e já sofreu 50 alterações até o ano de 2015 . 0 Plano possui uma primeira parte estratégica, enquanto a segunda caracteriza-se como aplicação direta, vinculada ao ordenamento territorial do município, embora se observe uma carência de conectividade entre as duas etapas. Destaca-se, também, que o PDDI 
de Passo Fundo apresenta conformidade com o Estatuto da Cidade (Lei 10.257/01) e contempla a aplicação de seus respectivos instrumentos, como o de indução do desenvolvimento urbano.

Quanto à promoção do desenvolvimento, econômico menciona o fortalecimento, diversificação, estímulo às novas vocações e o "estabelecimento de pólos produtivos vocacionados" (PREFEITURA..., 2006, p. 3), estes representados por centros de produção ou comerciais especializados, que envolvem as áreas de inovação e tecnologia e incubadoras. Estes ambientes normalmente não se identificam com as áreas urbanas centrais, ao contrário, com locais com outro padrão de uso e localizados em policentros urbanos. Embora exista esta determinação dos polos produtivos vocacionados não é possível identificar que ocorre um reconhecimento da existência de policentros no ambiente urbano de Passo Fundo (RS).

Na dinâmica das atividades econômicas urbanas, o setor industrial é o mais restritivo em relação à integração com os demais usos. Nesta seara existe uma perspectiva de continuidade de segregação ou confinamento espacial destas atividades, que são mais difíceis de serem integradas e miscigenadas com os demais usos, principalmente às geradoras de poluição e incomodidades à vizinhança. O Plano Diretor contempla a "disponibilização de áreas e infraestrutura necessárias para a implantação e ampliação de estabelecimentos industriais" (PREFEITURA..., 2006, p. 4).

A espacialização das atividades econômicas é fundamental para determinar as características da mobilidade populacional sobre o território urbano, uma vez que o polo das atividades comerciais e de serviços normalmente é localizado em ambiente central, se constitui como um atrativo de mão de obra - força centrífuga pela convergência e fluxos urbanos para a área central, conforme demonstrou Villaça (2001) em seus estudos. Neste cenário, a descentralização das atividades econômicas (policêntrico) também é um fator de "redução das distâncias a percorrer, das necessidades de deslocamento, e os tempos de viagem e dos custos operacionais", tanto para o cidadão quanto para as organizações (PREFEITURA..., 2006, p. 11).

O uso do solo urbano de forma miscigenada, para além da área urbana central, forma a cidade policêntrica; neste sentido o PDDI (PREFEITURA..., 2006, p. 13) oferece uma pista sobre a sua gênese, uma vez que a "descentralização dos equipamentos urbanos, no sentido de obter a adequada distribuição dos serviços públicos municipais", é importante para o processo de formação inicial de um policentro, ou seja, os serviços públicos são impulsionadores dos policentros, uma vez que se cristalizam por meio de equipamentos e infraestruturas públicas, tais como creches, escolas, unidades de saúde, postos de segurança pública, criam-se condições mais favoráveis para a diversificação dos usos, principalmente pela convergência populacional a estes ambientes.

A contemplação das áreas com usos mistos ou multifuncionais, mesclas entre residências e atividades econômicas, menciona os eixos indutores destas multifuncões, relacionados aos policentros, distribuídos no tecido urbano da cidade de Passo Fundo (PREFEITURA..., 2006, p. 19). Observa-se a contemplação dos policentros com base nas vias estruturantes urbanas, uma vez que também são indutoras da instalação de atividades econômicas conformes e permissíveis e se constituem como corredores intraurbanos e regionais; a forma linear se sobrepõe ao antigo polígono do centro, também 
comprovado em pesquisas de Ferrão (2012). Não se observa uma priorização de usos por atividades econômicas em ambientes policêntricos, apenas pela destinação dos usos diversificados ao longo das vias estruturantes urbanas.

Para as áreas urbanas centrais mais consolidadas, o Estudo de Impacto de Vizinhança (EIV) possui menor aplicabilidade, pela consolidação dos usos do solo, todavia, nas áreas policêntricas representa um importante mecanismo a ser utilizado pelo poder Executivo municipal para o ordenamento do uso do solo urbano, em conformidade com o Estatuto da Cidade (2001). Ademais, observa-se que os instrumentos do Estatuto da Cidade são pouco direcionados ao uso do solo por atividades econômicas, tais como o "Consórcio Imobiliário, Direito de Preempção, Outorga Onerosa do Direito de Construir, Operações Urbanas Consorciadas, Transferência do Direito de Construir e Direito de Superfície" (PREFEITURA..., 2006, p. 46-49), sendo esta também uma deficiência da literatura especializada.

Infere-se que o Plano Diretor de Desenvolvimento de Passo Fundo (2006) já não possui os elementos necessários para a aplicação da realidade complexa do atual tecido urbano, no que diz respeito ao uso do solo por atividades econômicas. Embora sua função principal seja a indução do desenvolvimento urbano, observa-se muitas generalidades e certa simplificação, inclusive em relação aos possíveis potenciais da aplicação dos instrumentos do Estatuto da Cidade (2001). Desta forma, este se caracteriza como fechamento de um ciclo útil e deve orientar a elaboração de nova legislação municipal, mais efetiva e adequada à realidade municipal e urbana, em período vindouro.

\section{Uso do Solo Monocêntrico e Policêntrico no Plano Diretor de Chapecó (SC)}

O município de Chapecó (SC), emancipado em 1917, pertence à mesorregião do Oeste de Santa Catarina, constitui-se como um polo regional, com população estimada em 213.279, conforme a estimativa do IBGE (INSTITUTO..., 2017). Sua base econômica está centrada no agronegócio de proteínas de carne, o que determina uma diversidade de usos urbanos centrados na indústria agroalimentar e metalmecânica. O comércio e serviços privados e públicos são prestados para uma população regional, o que influência nas características da sua funcionalidade econômica intraurbana.

O Plano Diretor do município de Chapecó (PDC) foi instituído pela Lei municipal n. 541, de 2014, e sofreu uma alteração em 2016, para a instituição de novos bairros, apresenta conformidade com o Estatuto da Cidade (Lei n. 10.257/01) e contempla a aplicação de seus respectivos instrumentos, como de indução do desenvolvimento urbano.

Entre seus objetivos destaca-se a preocupação em "ordenar o uso e ocupação do solo urbano, de forma a promover áreas para as diferentes atividades urbanas, sem que haja incompatibilidades de usos, observando a capacidade de suporte da infraestrutura" (PREFEITURA..., 2014, 4). Em sua parte estratégica o PDC (PREFEITURA..., 2014, p. 6) reconhece a existência da cidade policêntrica, por meio da "promoção do desenvolvimento econômico dos bairros e regiões da cidade, com vista à descentralização das atividades econômicas e à criação de novos polos geradores de serviços, empregos e rendas". Permite ainda a "coexistência de usos e atividades diversificadas, compatíveis 
entre si e com o uso residencial, evitando-se a segregação dos espaços, diminuindo os deslocamentos e contribuindo com o processo de descentralização das atividades econômicas".

Outro condicionante interessante que deveria ser referido ao se priorizar atividades econômicas descentralizadas é a "densidade populacional", neste caso, como um indicador adequado para que se possa flexibilizar o uso do solo por atividades econômicas - estas determinações podem ser vistas em estudos desenvolvidos por Souza (2004) e Villaça (2001).

No que diz respeito às atividades inovadoras, reporta para o apoio para a viabilização e criação "de parques ou distritos de natureza científica e tecnológica, como instrumento estratégico para o desenvolvimento econômico", inclusive pretende "estabelecer legislação tributária específica para as áreas consideradas aptas a sediar os parques" (PREFEITURA..., 2014, p. 15). Esta modalidade de usos é particularmente interessante e tende a se instalar em ambiente policêntrico, em novos espaços de produção do uso do solo urbano, portanto não se identificam com áreas urbanas centrais, com usos mais tradicionais, como o comércio. Para o ambiente urbano torna-se interessante, uma vez que, além de seus benefícios imediatos e diretos, pode promover uma maior equidade no uso do solo em áreas não centrais (monocêntrica), contribuindo para a minimização da segregação urbana (ver estudos de CLAYTON; MORRIS, 2010).

Cabe destacar que às vezes o ambiente policêntrico não surge de um planejamento municipal, mas por demandas espontâneas, como no caso da instalação de um equipamento de maior porte e que se torna uma referência de convergência populacional, em áreas pouco densificadas, periféricas, de uso exclusivo familiar, portanto monofuncional, com infraestrutura deficiente, carente de equipamentos urbanos e áreas de lazer, conforme descrito por Pessoa (2011). Neste caso, estas áreas necessitam de transformações urbanísticas, portanto também geram demandas públicas para a reversão destas debilidades. Isso implica custos fixos, por conseguinte, custos para o cidadão.

Quanto à oferta de infraestrutura, normalmente se processa em áreas urbanas centrais, entretanto, por um lado, deve-se considerar a superutilização em horário comercial (ver KEYNHANS apud COLLING; PIFFER, 2016), desta forma, ela não se constitui como suficiente, revelando-se um dos elementos importantes de desvitalização urbana em áreas monofuncionais. Por outro lado, estas áreas afugentam os investimentos para moradia e tendem a se tornar "vazias deste uso" no período noturno, gerando problemas de segurança pública. No enunciado do Plano Diretor de Chapecó não é possível identificar que existe um processo de desvitalização urbana da área central, principalmente dos corredores com maior concentração de atividades econômicas, portanto ela não deve receber políticas sistemáticas que visem à reconversão do atual cenário, com base neste Plano Diretor.

É importante destacar que o uso do solo urbano vai adquirindo novas configurações. Uma tendência interessante diz respeito à destinação do uso residencial, ou seja, o ambiente de moradia, como local possível ou apto ao consorciamento com o "desenvolvimento de atividades econômicas de pequeno porte e baixo potencial de degradação ambiental", inclusive em "áreas destinadas aos loteamentos de interesse popular ou social" (PREFEITURA..., 2014, p. 35, 72), independentemente de fazer parte da cidade monocêntrica ou policêntrica, embora com maiores possibilidades neste último, com 
usos multifuncionais, com geração de trabalho e renda na mesma edificação da moradia - independentemente da conjugação de pavimento horizontal ou vertical, conforme prevê Souza (2004).

\section{Uso do Solo Monocêntrico e Policêntrico no Plano Diretor de Cascavel (PR)}

O município de Cascavel (PR) foi emancipado em 1951, pertence à região Oeste paranaense e possui uma população de 319.608 , conforme a estimativa do IBGE (INSTITUTO..., 2017). Sua base econômica também é o agronegócio, amparado nos complexos de carnes e grãos. As atividades urbanas são diversificadas, típicas de um polo regional, com a formação de importantes atividades da indústria, como suporte ao agronegócio, de forma que influenciam na organização espacial intraurbana da cidade.

O Plano Diretor do município de Cascavel (PDC) foi instituído pela Lei municipal n. 028, de 2006 e sofreu apenas duas alterações posteriores, em 2012 e 2014. O Plano possui uma primeira parte estratégica enquanto a segunda se caracteriza como aplicada, vinculada ao ordenamento territorial do município de Cascavel. Diferente dos demais municípios, em Cascavel (PR) existe uma Lei Ordinária de Uso do Solo, separada e complementar ao Plano Diretor, portanto individual e elaborada em temporalidade posterior (Lei n. 6.179, 2013). O Plano Diretor de Cascavel apresenta conformidade com o Estatuto da Cidade e contempla a aplicação de seus respectivos instrumentos de política de desenvolvimento urbano, regularização fundiária e de gestão democrática e participativa. Interessante salientar que a Lei n. 6.157, de 2012, regulamentou a aplicação dos instrumentos da política urbana, previstos no Estatuto da Cidade (2001) e contempladas no Plano Diretor, de 2006.

Verifica-se que existe um vínculo do desenvolvimento que fica condicionado à expansão urbana, condição que deveria ser aferida com base em técnicas de medidas de dados, para a conferência da densidade urbana, determinada por vários fatores, entre os quais os vazios urbanos, tamanho dos lotes e níveis de verticalização urbana. Salienta-se que o controle da expansão urbana é diferente do perímetro urbano (PREFEITURA..., 2006b, p. 15).

Sobre a miscigenação do uso do solo urbano aporta para a "compatibilização das diferentes situações de uso e ocupação nas áreas urbanas visando à qualidade de vida dos habitantes", por meio de diretrizes, como a "permissão e a convivência de usos distintos desde que seja garantida a qualidade [...] da mobilidade e a acessibilidade universal" (PREFEITURA..., 2006b, p. 15). Esta estratégia evidencia a flexibilidade do Plano Diretor em relação aos usos predominantes e mistos: em parte podem ser conjugados com o uso residencial, comercial, serviços, inclusive atividades industriais específicas, sem incômodo à vizinhança. É evidente a preocupação com o ordenamento da "descentralização de atividades, por meio de uma política de policentralidade que considere a atividade econômica e a provisão de serviços" (PREFEITURA..., 2006b, p. 20) em regiões que não sejam vinculadas à área urbana central, portanto existe maior liberdade de regra para os usos urbanos, conforme mencionou Souza (2004).

Esta contemplação evidencia que a perspectiva de descentralização das atividades econômicas urbanas, desde que não causem incômodos e impactos no entorno, está amparada legalmente, fator que favorece o seu planejamento, bem como a captação de 
recursos públicos para o estabelecimento de infraestrutura de suporte, inclusive para prospecções futuras, caso não exista saturamento e conflitos de usos. Destaca-se que a descentralização das atividades econômicas, no ambiente urbano, que formam os policentros, não está em desacordo com o a política municipal de "contenção da expansão horizontal da cidade, voltada ao aproveitamento da utilização da infraestrutura existente e atendimento das diretrizes de estruturação do município" (PREFEITURA..., 2013, p. 28), uma vez que esta medida é interessante para a diminuição dos custos fixos urbanos, portanto são custos da sociedade, e para a diversificação das atividades econômicas, conforme afirmam Brandli et. al. (2015).

Para fins de gestão da área urbana central da cidade de Cascavel (PR), em área denominada de macrozona de estruturação e adensamento (PREFEITURA..., 2013, p. 33), menciona que o uso do solo deverá incentivar a ocorrência do uso residencial em consonância com o uso de comércio e serviço, como forma de evitar a degradação urbana. Observa-se a preocupação com a política de manutenção da vitalidade do ambiente urbano central. Inclusive como aporte a essa medida determina que as "áreas atendidas por infraestrutura básica serão receptoras de potencial construtivo transferido ou outorgado" (PREFEITURA..., 2013, p. 33), conforme prevê a Lei 10.257 (2001), portanto, vincula as ações interventivas do ambiente urbano central aos instrumentos do Estatuto da Cidade, para potencializar as condições adequadas de bem-estar, seja pela moradia, pelas atividades econômicas ou pelos frequentadores deste ambiente central.

Comumente a área urbana central, por ter processo de usos mais estável, também é vista como mais consolidada nas legislações municipais, desta forma, tem sido objeto de menor interferência por parte dos gestores, que não reconhecem seus processos de desvitalização ou de envelhecimento. Neste caso em análise, a contemplação deste fenômeno de desvitalização urbana pode orientar o desenvolvimento de programas públicos, inclusive em parceria com a iniciativa privada (aplicação dos instrumentos do Estatuto da Cidade, 2001 e parcerias, conforme Maricato, 2010), para a revitalização de áreas urbanas centrais. Também a orientação da descentralização do uso do solo por atividades econômicas impõe um desafio: a não repetição dos problemas estruturais que acometem as áreas urbanas centrais.

Observa-se a preocupação com a desvitalização com o "centro dos bairros" (força de expressão, pois a área urbana central também faz parte de um bairro) e vincula "à prioridade de investimentos públicos em termos de reurbanização" (PREFEITURA..., 2013, p. 14), uma vez que os policentros, que surgem como uma alternativa aos problemas urbanos centrais, tendem a repetir as mesmas deficiências estruturais, por isso também podem se desvitalizar, em grande parte, pela ausência de planejamento. Existe, desta forma, uma concorrência espacial, uma vez que diferentes ambientes urbanos se especializam na mesma produção do uso do solo, por atividades econômicas do comércio e dos serviços, em muitas situações criando condições desfavoráveis ao ambiente urbano central, que tende a se desvitalizar.

O Quadro 1 apresenta uma síntese dos Planos Diretores de Passo Fundo (RS), Chapecó (SC) e Cascavel (PR) quanto aos principais indicadores de espacialização das atividades econômicas urbanas, tanto em ambiente monocêntrico quanto no policêntrico. 
Quadro 1 - Características individuais dos Planos Diretores dos municípios da pesquisa

\begin{tabular}{|c|c|c|c|c|}
\hline \multicolumn{2}{|c|}{ Tema } & $\begin{array}{l}\text { Plano Diretor de } \\
\text { Passo Fundo (RS) }\end{array}$ & $\begin{array}{l}\text { Plano Diretor de } \\
\text { Chapecó (SC) }\end{array}$ & $\begin{array}{l}\text { Plano Diretor de } \\
\text { Cascavel (PR) }\end{array}$ \\
\hline \multirow{2}{*}{\multicolumn{2}{|c|}{$\begin{array}{l}\text { Ordenamento do solo } \\
\text { Maior rigidez no uso do solo }\end{array}$}} & Zoneamentos & Macrozonas & Macrozonas \\
\hline & & Uso do solo mais flexível & $\begin{array}{c}\text { Uso do solo mais fle- } \\
\text { xível }\end{array}$ & \\
\hline \multirow{3}{*}{$\begin{array}{l}\text { Área urbana } \\
\text { central }\end{array}$} & Usos & Mais tradicionais & Mais tradicionais & Mais tradicionais \\
\hline & Concepção uso & Mais consolidado & Mais consolidado & Mais consolidado \\
\hline & $\begin{array}{l}\text { Monocêntrica em } \\
\text { desvitalização }\end{array}$ & Não contempla & Não contempla & Contempla \\
\hline \multicolumn{2}{|c|}{ Revitalização da área urbana central } & Não contempla & Não contempla & Contempla \\
\hline \multirow{4}{*}{$\begin{array}{l}\text { Área urbana } \\
\text { descentralizada }\end{array}$} & Usos & $\begin{array}{c}\text { Mais diversificados e } \\
\text { inovadores }\end{array}$ & $\begin{array}{l}\text { Mais diversificados e } \\
\text { inovadores }\end{array}$ & $\begin{array}{l}\text { Mais diversificados e } \\
\text { inovadores }\end{array}$ \\
\hline & Concepção uso & $\begin{array}{l}\text { Orgânico, em transfor- } \\
\text { mação }\end{array}$ & $\begin{array}{l}\text { Orgânico, em transfor- } \\
\text { mação }\end{array}$ & $\begin{array}{l}\text { Orgânico, em transfor- } \\
\text { mação }\end{array}$ \\
\hline & \multirow{2}{*}{ Policêntrica } & Contempla & Contempla & Contempla \\
\hline & & Sem muita ênfase & Com ênfase & Com muita ênfase \\
\hline \multicolumn{2}{|c|}{$\begin{array}{l}\text { Laços de solidariedade entre mono- } \\
\text { cêntrico e policêntrico* }\end{array}$} & Não contempla & Não contempla & Não contempla \\
\hline \multicolumn{2}{|c|}{ Flexibilidade de usos } & $\begin{array}{l}\text { Para o ambiente mono- } \\
\text { cêntrico e policêntrico }\end{array}$ & $\begin{array}{l}\text { Para o ambiente mono- } \\
\text { cêntrico e policêntrico }\end{array}$ & $\begin{array}{l}\text { Para o ambiente mono- } \\
\text { cêntrico e policêntrico }\end{array}$ \\
\hline \multicolumn{2}{|c|}{ Miscigenação do uso do solo urbano } & $\begin{array}{l}\text { Com menor intensidade } \\
\text { para o ambiente mono- } \\
\text { cêntrico e maior intensi- } \\
\text { dade para o policêntrico }\end{array}$ & $\begin{array}{l}\text { Com menor intensidade } \\
\text { para o ambiente mono- } \\
\text { cêntrico e maior intensi- } \\
\text { dade para o policêntrico }\end{array}$ & $\begin{array}{l}\text { Intenso para o am- } \\
\text { biente monocêntrico e } \\
\text { policêntrico }\end{array}$ \\
\hline \multirow{2}{*}{\multicolumn{2}{|c|}{$\begin{array}{l}\text { Atividades de produção econômica } \\
\text { fora do perímetro urbano } \\
\text { Indústrias localizadas de forma linear } \\
\text { nos acessos regionais }\end{array}$}} & Permitido & Permitido & Permitido com ênfase \\
\hline & & $\begin{array}{l}\text { Indústrias localizadas de } \\
\text { forma linear nos acessos } \\
\text { regionais }\end{array}$ & $\begin{array}{l}\text { Ordenamento das sedes } \\
\text { distritais e indústrias } \\
\text { localizadas de forma } \\
\text { linear nos acessos re- } \\
\text { gionais }\end{array}$ & \\
\hline \multicolumn{2}{|c|}{$\begin{array}{c}\text { Aplicação dos Instrumentos do Esta- } \\
\text { tuto da Cidade }\end{array}$} & $\begin{array}{l}\text { Contempla todos os } \\
\text { Instrumentos, mas não } \\
\text { aplica para revitalização } \\
\text { de área urbana central }\end{array}$ & $\begin{array}{l}\text { Contempla todos os } \\
\text { Instrumentos, mas não } \\
\text { aplica para revitalização } \\
\text { de área urbana central }\end{array}$ & $\begin{array}{l}\text { Contempla todos os } \\
\text { Instrumentos e aplica } \\
\text { para a revitalização de } \\
\text { área urbana central }\end{array}$ \\
\hline \multicolumn{2}{|c|}{$\begin{array}{l}\text { Vínculo dos instrumentos do Estatu- } \\
\text { to da Cidade com o uso do solo por } \\
\text { atividades econômicas }\end{array}$} & $\begin{array}{l}\text { Praticamente inexisten- } \\
\text { te, exceto em parceria } \\
\text { público- privada, EIV } \\
\text { e EIA }\end{array}$ & $\begin{array}{l}\text { Praticamente inexisten- } \\
\text { te, exceto em parceria } \\
\text { público- privada, EIV } \\
\text { e EIA }\end{array}$ & $\begin{array}{l}\text { Existente na parceria } \\
\text { público-privada, EIV e } \\
\text { EIA e certa integração } \\
\text { dos demais instrumen- } \\
\text { tos e o uso do solo com } \\
\text { a produção econômica }\end{array}$ \\
\hline \multicolumn{2}{|c|}{$\begin{array}{c}\text { Previsão de usos por atividades ino- } \\
\text { vadoras }\end{array}$} & Não contempla & $\begin{array}{l}\text { Contempla em policen- } \\
\text { tros }\end{array}$ & Não contempla \\
\hline
\end{tabular}

* Existência de relação de complementaridade entre o uso do solo urbano por atividade econômica entre os dois ambientes.

Fonte: PREFEITURA MUNICIPAL DE PASSO FUNDO, 2006, PREFEITURA MUNICIPAL DE CHAPECó, 2014, PREFEITURA MUNICIPAL DE CASCAVEL, 2006a, b.

\section{CONCLUSÕES DA PESQUISA}

Nos três Planos Diretores que foram objeto desta pesquisa observa-se diferentes concepções em seus processos de constituição e que refletem nas suas aplicações em período de vigência: os de Chapecó (SC) e Cascavel (PR) possuem maior flexibilidade do uso do solo, enquanto que Passo Fundo (RS) é mais rígido, regulamentador, e de certa forma já não atende mais às atuais demandas do uso do solo por atividades econômi- 
cas. Quanto ao uso do solo urbano em área central, por ser mais consolidado, o Plano Diretor possui mais restrições de aplicação, acrescido pelo não reconhecimento da desvitalização destas áreas, exceto em Cascavel (PR).

Quanto às áreas urbanas de descentralização do desenvolvimento, chamados policentros, existe uma maior previsão de flexibilização e miscigenação do uso do solo urbano, normalmente possui uma perspectiva linear ao invés de poligonal, pois as vias de ligação entre os bairros e regionais são indutoras deste desenvolvimento, não mais o polígono, como no centro da cidade - altera-se o padrão de desenvolvimento intraurbano. Estas áreas policêntricas possuem um potencial para a promoção de maior equilíbrio urbano, portanto de diminuição das assimetrias intraurbanas, embora, em determinados casos, podem contribuir significativamente para a redução da densidade relacional da área central monocêntrica.

Assim sendo, para além das atividades tradicionais, não se observa uma priorização de usos por atividades econômicas específicas em ambientes policêntricos, apenas pela destinação dos usos diversificados, onde se inclui os polos produtivos vocacionados, parques ou distritos de natureza científica e tecnológica, que quase sempre necessitam de impulso de política pública complementar, como de incentivo ao desenvolvimento econômico e regulamentado por legislação específica. Esta modalidade de usos tende a se instalar em ambiente policêntrico, em novos espaços de produção do uso do solo urbano, portanto não se identifica com áreas urbanas centrais, com usos mais tradicionais, neste caso refere-se às atividades comerciais.

Embora os policentros sejam elementos que interferem na descontinuidade da força centrífuga de áreas centrais, ressalta-se que este fenômeno é muito mais determinado por fatores próprios do ambiente monocêntrico, que tendem a apresentar um processo falimentar, desde que não sofram interferências públicas sistemáticas e severas, muitas vezes ineficientes, em longo prazo (estas interferências são chamadas de mudança com permanência). A dinamização do ambiente monocêntrico está condicionada à presença de serviços públicos administrativos, que ainda tendem a se localizar no centro (terras e edificações públicas), reforçando a função do ambiente monocêntrico de continuidade de atração populacional, aliado ao comércio de pequeno porte, polo gerador de tráfego.

Nos três Planos Diretores não se observou uma integração espacial entre áreas centrais monocêntricas com os policentros, demonstrando uma visão com certa fragmentação do ambiente urbano, ainda pensado de forma pouco integrativa e sistemática, reflexo do planejamento com base em zoneamentos monofuncionais utilizados em período pretérito, nos respectivos processos de planejamento de cidades.

Todos os Planos Diretores contemplam os instrumentos do Estatuto da Cidade, mas não os aplicam para revitalização de área urbana central, muito menos os vinculam ao uso do solo por atividades econômicas, potencial praticamente inexplorado, na atualidade, que proporcionaria um aporte para as políticas de desenvolvimento, no que diz respeito a uma maior equidade em relação à distribuição das atividades econômicas no ambiente urbano. Ainda pelo perfil econômico destas cidades médias, destaca-se que o setor industrial é o mais restritivo em relação à integração com os demais usos. Nesta perspectiva tende a existir a continuidade de segregação ou confinamento espacial de parte significativa destas atividades. 
Destaca-se ainda que o Plano Diretor deve ser elaborado como uma nova agenda urbana em relação a sua constituição, que contribui para um uso do solo mais flexível e miscigenado, resultando em uma cidade mais compacta e com menores dissimetrias. Estas características espaciais se constituem um desafio na nova configuração urbana, por atividades econômicas mescladas por outros usos em cidades médias.

Por fim, o conhecimento destas características do ambiente monocêntrico e policêntrico, que se constituem nos ambientes de concentração de atividades econômicas urbanas, também é relevante e estratégico para os gestores de firmas da iniciativa privada, uma vez que pode orientar tendências da espacialização e investimentos futuros, tanto da iniciativa privada quanto para o planejamento e gerenciamento público da infraestrutura e equipamentos urbanos disponíveis neste ambiente, além de contribuir para uma minimização da segregação espacial urbana, com base na mobilidade das atividades econômicas em ambiente intraurbano.

\section{REFERÊNCIAS}

ACSELRAD, H. A duração das cidades: sustentabilidade e risco nas políticas urbanas. 2. ed. Rio de Janeiro: Ed. Lamparina, 2009.

AMORIM FILHO, O. B. Um esquema metodológico para o estudo das cidades médias. ENCONTRO NACIONAL DE GEÓGRAFOS, 1976. Belo Horizonte. Anais... Belo Horizonte: IGC; UFMG, 1976. p. 6-15.

ANTONELLO, I. T. Potencialidade do planejamento participativo no Brasil. Sociedade \& Natureza, v. 25, n. 2, p. 239-254, 2013. Disponível em: <http://www.scielo.br/pdf/sn/v25n2/a03v25n2.pdf>. Acesso em: 14 jan. 2017.

BRANDLI, L. et al. Gestão urbana no Rio Grande do Sul: perspectivas para a sustentabilidade. In: Sistemas \& Gestão, n. 10, p. 526-541, 2015. Disponível em: <http://www.revistasg.uff.br/index.php/sg/article/ view/V10N3A14/SGV10N3A14>. Acesso em: 22 jan. 2017.

BRASIL. Constituição Federal de 1988: artigos 182 e 183. Brasília, 1988. Disponível em: <http://www.planalto.gov.br/ccivil_03/constituicao/ConstituicaoCompilado.htm>. Acesso em: 9 jan. 2017.

CARVALHO PINTO, V. Direito urbanístico: Plano Diretor e direito de propriedade. 3. ed. rev. e atual. São Paulo: Ed. Revista dos Tribunais, 2011.

CASTELLS, M. A questão urbana. Trad. Arlene Caetano. 3. ed. Rio de Janeiro: Ed. Paz e Terra, 2006.

CLAYTON, N.; MORRIS, K. Recession, Recovery and Medium-Sized Cities. 2010. Disponível em: <http:// www.redbcm.com.br/arquivos/bibliografia/recession,\%20recovery\%20and\%20medium-sized\%20cities. pdf>. Acesso em: 8 jan. 2017.

COLLING, M. A.; PIFFER, M. Corredores de desenvolvimento: conceito e aplicação. Desenvolvimento em Questão, ljuí: Ed. Unijuí, ano 14, n. 36, out./dez. 2016. Disponível em: <https://www.revistas.unijui.edu. br/index.php/desenvolvimentoemquestao/article/view/3201/5043>. Acesso em: 27 out. 2017.

COOPER, D. R.; SCHINDLER, P. S. Métodos de pesquisa em administração. Trad. luri Duquia Abreu. 10. ed. Porto Alegre: Bookman, 2011.

ESTATUTO DA CIDADE. Lei 10.267, de 28 de agosto de 2001. Altera dispositivos das Leis n. 4.947, de 6 de abril de 1966 e outras... e dá outras providências. Brasília, 2001.

FERRÃO, J. (Coord.). Functional regions, urban-rural relations and post-2013 cohesion policy - final report. Lisboa, Portugal: Universidade de Lisboa, 2012.

FERRARI, R. M. M. N. Direito Municipal. 3. ed. rev. atual. e ampl. São Paulo: Ed. Revista dos Tribunais, 2012.

FONTES FILHO, J. R.; BRONSTEIN, M. M.; PIMENTA, G. A. Conselhos municipais: a importância da participação e da confiança para os novos modelos de governança. ENANPAD, 39., 2015. Belo Horizonte, 2015. Disponível em: <http://www.anpad.org.br/ anpad/abrir_pdf.php?e=MTkzMTA=>. Acesso em: 4 jan. 2017.

GOMES, M. T. S. Cidades médias, novos espaços produtivos e reestruturação do espaço urbano em Uberaba-MG. In: Revista Franco-brasileira de Geografia - Confins, n. 25, 2015. Disponível em: <https://confins.revues.org/10407>. Acesso em: 26 jan. 2017.

INSTITUTO BRASILEIRO DE GEOGRAFIA E ESTATÍSTICA - IBGE. Redes e fluxos do território: gestão do território. Rio de Janeiro, 2014. 
INSTITUTO BRASILEIRO DE GEOGRAFIA E ESTATÍSTICA - IBGE. Cidades e Estados do Brasil: estimativa populacional de 2017. Rio de Janeiro, 2017. Disponível em: <https://www.ibge.gov.br/geociencias-novoportal/organizacao-do-territorio/estrutura-territorial/15761-areas-dos-municipios.html?t=destaques\&c=4104808>. Acesso em: 2 nov. 2017.

KRAFTA, R. Modelling Intra urban configurational development. In: Environment and Planning B: Planning and Design, (21), p. 67-82, 1997.

LEITE, C.; AWARD, J. di C. M. Cidades sustentáveis, cidades inteligentes: desenvolvimento sustentável num planeta urbano. Porto Alegre: Bookman, 2012 (E-book). Disponível em: <https://books.google.com.br/ books?id=aV2GDQtQuAYC\&pg=PA6\&lpg=PA6\&dq=Paul+Krugman...>. Acesso em: 15 fev. 2017.

MARICATO, E. O estatuto da cidade periférica. In: O Estatuto da Cidade: comentado. São Paulo: Ministério das Cidades; Aliança das Cidades, 2010.

PESSOA, R. P. P. Em busca de uma definição de policentrismo urbano para as metrópoles brasileiras. Revista Paranaense de Desenvolvimento, Curitiba, n. 120, p. 297-318, jan./jun. 2011. Disponível em: <http:// www.ipardes.pr.gov.br/ojs/index.php/revistaparanaense/article/viewFile/198/679>. Acesso em: 7 mar. 2017.

PREFEITURA MUNICIPAL DE CASCAVEL. Lei Complementar $n$ ㅇ 028 de 2016: regulamenta a aplicação dos instrumentos da política urbana do Plano Diretor do município de Cascavel. Cascavel (PR), 2006. Disponível em: <https://leismunicipais.com.br/a1/plano-diretor-cascavel-pr>. Acesso em: 9 mar. 2017.

Lei $n$ o 6.179 de 17 de janeiro de 2013: dispõe sobre o uso do solo no município de Cascavel. Cascavel (PR), 2013. Disponível em: <https://leismunicipais.com.br/pdf/Lei-ordinaria-6179-2013-Cascavel-PR-consolidada-\%5B07-08-2015\%5D.pdf>. Acesso em: 9 mar. 2017.

PREFEITURA MUNICIPAL DE CHAPECÓ. Lei Complementar no 541 de 26 de novembro de 2014: aprova o Plano Diretor de Chapecó - PDC. Chapecó (SC), 2014. Disponível em: <https://leismunicipais.com.br/ pdf/Lei-complementar-541-2014-Chapeco-SC-consolidada-\%5B14-12-2015\%5D.pdf>. Acesso em: 9 mar. 2017.

PREFEITURA MUNICIPAL DE PASSO FUNDO. Lei Complementar no 170 de 9 de outubro de 2006: dispõe sobre o Plano Diretor de Desenvolvimento Integrado - PDDI - do município de Passo Fundo (RS). Passo Fundo (RS), 2006. Disponível em: <https://leismunicipais.com.br/a1/plano-diretor-passo-fundo-rs-2015-10-23-versao-consolidada>. Acesso em: 9 mar. 2017.

PROGRAMA CIDADES SUSTENTÁVEIS. Programa Cidades Sustentáveis. Secretaria Executiva da Rede Nossa São Paulo. Disponível em: <http://www.cidadessustentaveis.org.br/downloads/publicacoes/publicacao-programa-cidades-sustentaveis.pdf>. Acesso em: 22 jan. 2017.

PUJADAS, R.; FONT. J. Ordenación y planificación territorial. Madrid: Editorial Sintesis, 1998.

RAMOS, E. F.; MATOS, R. E. da S.; GARCIA, R. A. As cidades médias como nódulos de equilíbrio da rede de cidades. Revista Paranaense de Desenvolvimento, Curitiba, n. 121, p. 41-63, jul./dez. 2011. Disponível em: <http://www.ipardes.pr.gov.br/ojs/index.php/revistaparanaense/article/view/424/687>. Acesso em: 4 jan. 2017.

SABOYA, R. T. de. Fundamentos conceituais para uma teoria do planejamento urbano baseada em decisões. Urbe - Revista Brasileira de Gestão Urbana, v. 5, n. 2, 2013. Disponível em: <http://www2.pucpr.br/ $\mathrm{reol} / \mathrm{pb} /$ index.php/urbe?dd1=12292\&dd99=view\&dd98=pb>. Acesso em: 13 jan. 2017.

SAULE JÚNIOR, N.; ROLNIK, R. Estatuto da cidade: novos horizontes para a reforma urbana. São Paulo: Polis, 2001.

SCHÄEFFER, N. O. Do armazém da esquina ao shopping center: a transformação do consumo de Porto Alegre. In: PANIZZI, W. M; ROVATTI, J. F. Estudos urbanos: Porto Alegre e seu planejamento. Porto Alegre: Ed. da Universidade da UFRGS, 1993.

SOUZA, M. L. de. Mudar a cidade: uma introdução crítica ao planejamento e à gestão urbanos. 3. ed. Rio de Janeiro: Bertrand Brasil, 2004.

SPOSITO, M. E. B. Novos conteúdos nas periferias urbanas das cidades médias do Estado de São Paulo, Brasil. Investigaciones Geográficas, Universidad Nacional Autónoma de México, n. 54, p. 114-139, ago. 2004. Disponível em: <http://www.redbcm.com.br/arquivos/bibliografia/novos\%20conte\%C3\%BAdos... pdf>. Acesso em: 8 jan. 2017.

VILLAÇA, F. Espaço intraurbano no Brasil. 2. ed. São Paulo: Studio Nobel; Fapesp; Lincoln Institute, 2001. 